\section{Re: Future of Board Certification in a New Era of Public Accountability}

To the Editor: Dr Weiss' ${ }^{1}$ article wisely calls for continuous modification of the board certification process to meet the needs of physicians and the general public. I believe that obtaining and maintaining certification should be required for licensure of all physicians.

In my field of internal medicine, those physicians who became board certified after 1992 (myself included) are required to recertify every 10 years at significant cost (currently \$1,570). ${ }^{2}$ Ironically, those who created this policy do not have to recertify, unless required to do so by their employers. Given the costs associated with recertification (recertification fee plus time lost from work or vacation to take the examination), this amounts to a regressive tax, since it falls more heavily on younger physicians who have spent fewer years in practice and may have lower incomes and higher educational debts.

In addition to being fair, requiring recertification for all practicing physicians may improve quality of care. One study found some evidence that physicians who had graduated from medical school more than 20 years ago were more likely to score in the lowest quartile on the Maintenance of Certification examination for internal medicine and do worse on some performance measures for Medicare patients. ${ }^{3}$ In a systematic review of data relating experience and age to physician performance, $70 \%$ of studies demonstrated a negative association between length of time in practice and several measures of good physician performance. ${ }^{4}$ It would be interesting to know how many academic medical centers require their more senior faculty to maintain board certification, given that these institutions function as leaders in education and policy.

Furthermore, consideration should be given to creating a national medical license. Having obtained a number of state licenses over the years myself (consequent to brief locum tenens stints between residency and fellowship), the process of licensing by state boards places a financial burden on physicians (separate fees for each state) and creates a large administrative burden. Having separate state licensing boards may not efficiently root out bad physicians who leave one state under a cloud of suspicion only to have their trails of malfeasance rooted out later because state reports regarding physicians who have been disciplined for unethical and/or illegal activity are not always readily available to other states or to the general public, ${ }^{5}$ even since the establishment of the National Practitioner Data Bank.

Martin Donohoe, MD

School of Community Health, Portland State University Kaiser Sunnyside Medical Center Portland, OR martindonohoe@phsj.org http://www.publichealthandsocialjustice.org

\section{References}

1. Weiss KB. Future of board certification in a new era of public accountability. J Am Board Fam Med 2010;23(Suppl 1): S32-9.

2. American Board of Internal Medicine. ABIM Maintenance of Certification exam schedule. Available at http://www.abim. org/exam/schedule-moc.aspx. Accessed 30 October 2009.

3. Holmboe ES, Wang Y, Meehan TP, et al. Association between maintenance of certification examination scores and quality of care for Medicare beneficiaries. Arch Intern Med 2008;168:1396-403.

4. Choudhry NK, Fletcher RH, Soumerai SB. Systematic review: the relationship between clinical experience and quality of health care. Ann Intern Med 2005;142:260-73.

5. Larson M, Lurie P, Marcus B, Wolfe S. Survey of state medical and osteopathy board disciplinary web sites in 2006. Health Matrix Clevel 2009 Winter;19:121-36.

doi: 10.3122/jabfm.2010.05.100115

The above letter was referred to the authors of the article in question, who offer the following reply.

\section{Response: Re: Future of Board Certification in a New Era of Public Accountability}

To the Editor: It is reassuring to hear from readers like Dr. Donohoe, ${ }^{1}$ who have embraced the concept of American Board of Medical Specialties (ABMS) Maintenance of Certification (MOC). In his letter he expresses concern about who is required to participate in MOC, and states, "those who created this policy do not have to recertify." In fact, Dr. Donohoe's certifying board, the American Board of Internal Medicine, requires its board members to recertify regardless of the status of their original certification. This is true of other member boards of the ABMS as well.

Dr. Donohoe also raises the issue of physicians who were certified before the ABMS and its 24 member boards developed the common standard of term-limited certificates. Because these physicians were presented with certificates that did not require recertification, they are not required to participate in MOC programs offered by ABMS member boards. Dr. Donohoe cited research suggesting that these physicians may be ideal candidates to benefit from MOC. Although most of the ABMS member boards have a policy of voluntary participation in MOC for these physicians, we are closely monitoring the emerging evidence related to this issue and how it might change future standards. In the meantime, our policy is to actively encourage physicians with non-time-limited certificates to voluntarily engage in MOC as a way to improve their ongoing competence and provide their patients with a reliable measure of physician accountability. 
One new effort is our alignment of the MOC program with the Physicians Quality Reporting Initiative of the US Centers for Medicare \& Medicaid Services (CMS). In the recently passed health care reform legislation (US Patient Protection and Accountable Care Act), there is a provision that enables physicians to meet the requirements of Physicians Quality Reporting Initiative and receive a bonus from CMS by participating in an ABMS member board MOC program. ABMS is working with CMS to launch this program in 2011.

However as noted in the paper referenced by Dr. Donohoe, ${ }^{2}$ ultimately, ABMS and its member boards seek to elevate the quality of patient care by providing physicians with an ongoing process of assessment and continuous professional development that requires participants to demonstrate clinical competency and keep pace with advances in the field of medicine throughout their entire careers. Although Dr. Donohoe's letter relating his personal experience with MOC is anecdotal, it reinforces what we've heard time and again from participating physicians: MOC results in better care for their patients.

Kevin B. Weiss, MD President and CEO, American Board of Medical Specialties Chicago, IL kweiss@ABMS.org

\section{References}

1. Donohoe M. Re: future of board certification in a new era of public accountability. J Am Board Fam Med 2010;23:687.

2. Weiss KB. Future of board certification in a new era of public accountability. J Am Board Fam Med 2010;23(Suppl 1):S32-9.

doi: $10.3122 /$ jabfm.2010.05.100175

\section{Re: Parental Acceptance of a Mandatory Human Papillomavirus (HPV) Vaccination Program}

To the Editor: An estimated 6,2 million women are infected every year with the human papillomavirus (HPV) in the United States, but the acceptance of the HPV vaccination is low; therefore, improving vaccination uptake is a demanding issue. ${ }^{1,2}$

Compared with several countries and especially the developing world, where the costs of the HPV vaccine must drop for access to improve, in the United States most large insurance plans cover the costs of approximately $\$ 125$ for each of the 3 doses, and children (up to 18 years old) may be eligible through the Vaccines for Children program.

In Germany, the cost is currently approximately $\$ 235$ US for one dose; however, according to the National Committee on Vaccination, for girls in the 12- to 18year-old age group the statutory health insurance covers the costs completely, and, on request, also provides coverage for older women. ${ }^{3}$ A study conducted in March 2010 among 298 female high school students in Leipzig,
Germany, shows that $59 \%$ of the participants were aware of the coverage by health insurance. Nonetheless, the acceptance of the vaccine is suboptimal. Despite complete financial coverage, in 2007 only $3.51 \%$ of 147,014 girls eligible for Gardasil received the vaccine. ${ }^{4}$

Although the use of the HPV vaccination has been improving recently, this finding is, unfortunately, similar to that of numerous other industrial countries (eg, Austria reported a vaccination rate of $4 \%$ in 2010). ${ }^{5}$ Information about the vaccination is widely spread in Germany, mainly by the media; however, $21.8 \%$ of the participants in our study had been informed about the vaccine by their family physician. Furthermore, $56.7 \%$ of the students indicated that they would prefer to be approached and counseled by their family doctor. Several studies revealed that parents value the information and recommendations provided by their children's health care providers. ${ }^{6}$ Although each encounter with an eligible patient might be considered an opportunity to encourage HPV vaccination, recent data show that family doctors are reluctant to recommend the vaccination mainly because of the controversial discussion in Germany about the benefits and efficacy and the concern of the vaccine's possible negative, long-term side effects. ${ }^{7,8}$ In addition, several family doctors feel uncomfortable about discussing sexuality issues with adolescent patients. ${ }^{9}$ Compared with South Korea, where the first cohabitation takes place, on average, at age 20, in Germany the average age is 15.1 years, according to the Federal Center for Health Education. ${ }^{10}$ Therefore, if family physicians would consider approaching young women-focusing on those younger than 15-to help them make informed decisions, it might contribute to an increase the level of vaccination.

Heide B. Schneider, MD, PhD

Department of Family Medicine University of Leipzig, Leipzig, Germany hbschneider@medizin.uni-leipzig.de

\section{References}

1. Ferris D, Horn L, Waller JL. Parental acceptance of a mandatory human papillomavirus (HPV) vaccination program. J Am Board Fam Med 2010;23:220-9.

2. Centers for Disease Control and Prevention. Sexually transmitted diseases: HPV vaccine information for young women. Available at http://www.cdc.gov/std/hpv/STDFact-HPVvaccine-young-women.htm. Accessed 29 July 2010.

3. Mitteilung der STIKO am Robert-Koch-Institut. Impfung gegen HPV für mädchen von 12-18 jahren: empfehlung und begründung. Epidemiol Bulletin 2007;12:97-103.

4. Buchberger B, Jahn R, Lux G. Erste Ergebnisse zur HPV-Impfung aus Routinedaten im Jahr 2007: HPV eine Erfolgsgeschichte? Available at www.mm.uni-due.de/ HPV_Poster_GMDS_Stand_010909_Version4.pdf. Accessed 29 July 2010.

5. Grossberger L. HPV Impfraten müssen steigen. MMA Medical Tribune 2010;10:42.

6. Zimet GD. Improving adolescent health: focus on HPV vaccine acceptance. J Adoles Health 2005;37:17-23.

7. Gerhardus A. Gebärmutterhalskrebs: wie wirksam ist die HPV- impfung? Dtsch Arztebl 2009;106:A330. 